Agnieszka Golczyńska-Grondas

Department of Applied Sociology and Social Work Institute of Sociology

Faculty of Economics and Sociology

University of Lodz, Poland

\title{
Tribute to Professor Fritz Schütze
}

DOI: https://doi.org/10.18778/1733-8077.10.1.15

P ofessor Fritz Schütze - as a person who had influenced my professional development - has become, for me, an important institutional significant other. As many other students of sociology in the Institute of Sociology, University of Lodz, in the late 80 s, I was attracted by the idea of autobiographical narrative interview, in that time - "a new tool for sociological field research" (Hermanns 1987). In the beginning, this enthrallment was rather theoretical - I did not decide to apply the biographical method in my M.A. thesis, as some of my "studymates" did. In 1990, I had the first opportunity to participate in a conjoint Polish-German workshop dedicated to the analysis of narrations, organized in Kassel. During this workshop I became acquainted with Professor Schütze, I also met his German associates. Even now, after almost 25 years, I can recall a very inspiring atmosphere of our collective work, and the hospitality of the German team and Professor Schütze himself. In the mid 90s, I befell the person responsible for the analytical tasks based on biographical interviews with social work institution clients as part of the research projects on poverty and social exclusion developed by the Department of Applied Sociology and Social Work, and I began to run biographical and autobiographical narrative interviews myself. A decade later, between 20032006, I had a privilege to work in the "INVITE" consortium as the coordinator of the Polish team.

“INVITE. New Ways of Biographical Counselling in Vocational Rehabilitation Training" was an international research project conducted within the framework of the Leonardo da Vinci Program. The interdisciplinary group composed of academics in the area of sociology and practitioners - psychologists, vocational counselors, and social workers from Finland, Germany, Italy, Poland, and Wales was coordinated by Otto von Guericke University in Magdeburg in the persons of Fritz Schütze and Peter Straus. The main result of the project was the educational curriculum on biographical method application in vocational counseling and social work presented in the form of 15 interlinked modules (CD, European Studies on Inequalities and Social Cohesion 1-2/2008 and 3-4/2008). Therefore, sociological, scientific concepts and research procedures have been converted into the professional counseling tool, an instrument of training clients to explore their life and motivating them to do biographical work. In the very idea of the "INVITE" project one can notice both the "habitual" interpretative sociologists' concern with the professional intervention development, and the continuation of Professor Schütze's specific interest in the field of professional (social) work, with its conditionings and paradoxes.

Three years of shared endeavor were the unique experience for the "INVITE" contributors due to the work culture ensured by Professor Schütze's leadership and his substantive supervision. He guided the project meetings in the way which enhanced individual and collective participation, as well as creativity, and generated the stimulating atmosphere of equal involvement and contribution for all team members, despite their age, vocational background, and formal position. It was a formative experience of scrupulous, reciprocal scientific work, all the more reason valuable during those days when the scientists, even in the field of social research, succumbed to the temptation of rivalry and superficial success. The in-depth, careful analysis of every single interview, and Professor's interest in practical usage of scientific work, guaranteed that the narrators' input

was not wasted - this notion is especially important in the research with traumatized and vulnerable groups. In my personal carrier, the involvement in the "INVITE" project has resulted in developing interest in the issues of identity, the importance of significant others for identity formation, and life course of social actors in the social worlds of poverty and marginalization.

In addition, allow me to emphasize that it is a great pleasure to meet Professor Fritz Schütze in the situations of more "unceremonious" character. Conference/project dinners and other forms of leisure time during formal gatherings give the opportunity to get to know Professor Schütze as a very open person, with an enormous spectrum of interests, tender-hearted, and always concerned with others and their stories, fascinated by new discoveries and findings, enchanted by richness of social life with a juvenescent curiosity.

Dear Fritz, in the year of your jubilee, I wish you all the best in your further scientific projects and endeavors, and in your everyday life.

\section{References}

Hermanns, Harry. 1987. “Narrative Interview - a New Tool for Sociological Field Research.” Pp. $43-56$ in Approaches to the Study of Face to Face Interaction, edited by Z. Bokszański, M. Czyżewski. Folia Sociologica 13. Lodz: Wydawnictwo Uniwersytetu Łódzkiego. 